NASA/TM-2001-211085

\title{
A Performance Map for Ideal Air Breathing Pulse Detonation Engines
}

Daniel E. Paxson

Glenn Research Center, Cleveland, Ohio 
Since its founding, NASA has been dedicated to the advancement of aeronautics and space science. The NASA Scientific and Technical Information (STI) Program Office plays a key part in helping NASA maintain this important role.

The NASA STI Program Office is operated by Langley Research Center, the Lead Center for NASA's scientific and technical information. The NASA STI Program Office provides access to the NASA STI Database, the largest collection of aeronautical and space science STI in the world. The Program Office is also NASA's institutional mechanism for disseminating the results of its research and development activities. These results are published by NASA in the NASA STI Report Series, which includes the following report types:

- $\quad$ TECHNICAL PUBLICATION. Reports of completed research or a major significant phase of research that present the results of NASA programs and include extensive data or theoretical analysis. Includes compilations of significant scientific and technical data and information deemed to be of continuing reference value. NASA's counterpart of peerreviewed formal professional papers but has less stringent limitations on manuscript length and extent of graphic presentations.

- TECHNICAL MEMORANDUM. Scientific and technical findings that are preliminary or of specialized interest, e.g., quick release reports, working papers, and bibliographies that contain minimal annotation. Does not contain extensive analysis.

- CONTRACTOR REPORT. Scientific and technical findings by NASA-sponsored contractors and grantees.
- CONFERENCE PUBLICATION. Collected papers from scientific and technical conferences, symposia, seminars, or other meetings sponsored or cosponsored by NASA.

- SPECIAL PUBLICATION. Scientific, technical, or historical information from NASA programs, projects, and missions, often concerned with subjects having substantial public interest.

- TECHNICAL TRANSLATION. Englishlanguage translations of foreign scientific and technical material pertinent to NASA's mission.

Specialized services that complement the STI Program Office's diverse offerings include creating custom thesauri, building customized data bases, organizing and publishing research results ... even providing videos.

For more information about the NASA STI Program Office, see the following:

- Access the NASA STI Program Home Page at http://www.sti.nasa.gov

- E-mail your question via the Internet to help@sti.nasa.gov

- Fax your question to the NASA Access Help Desk at 301-621-0134

- Telephone the NASA Access Help Desk at 301-621-0390

- Write to:

NASA Access Help Desk

NASA Center for AeroSpace Information 7121 Standard Drive

Hanover, MD 21076 


\section{A Performance Map for Ideal Air Breathing Pulse Detonation Engines}

Daniel E. Paxson

Glenn Research Center, Cleveland, Ohio

Prepared for the

37th Joint Propulsion Conference and Exhibit

cosponsored by the AIAA, ASME, SAE, and ASEE

Salt Lake City, Utah, July 8-11, 2001

National Aeronautics and

Space Administration

Glenn Research Center 
This report is a formal draft or working paper, intended to solicit comments and ideas from a technical peer group.

This report contains preliminary
findings, subject to revision as
analysis proceeds.

Available from

NASA Center for Aerospace Information 7121 Standard Drive

Hanover, MD 21076
National Technical Information Service 5285 Port Royal Road Springfield, VA 22100 
AIAA-2001-3465

\title{
A PERFORMANCE MAP FOR IDEAL AIR BREATHING PULSE DETONATION ENGINES
}

\author{
Daniel E. Paxson \\ National Aeronautics and Space Administration \\ Glenn Research Center \\ Cleveland, Ohio, USA \\ Phone: 216-433-8334, Fax: 216-433-8643 \\ Email: Daniel.E.Paxson@grc.nasa.gov
}

\begin{abstract}
The performance of an ideal, air breathing Pulse Detonation Engine is described in a manner that is useful for application studies (e.g. as a stand-alone, propulsion system, in combined cycles, or in hybrid turbomachinery cycles). It is shown that the Pulse Detonation Engine may be characterized by an averaged total pressure ratio, which is a unique function of the inlet temperature, the fraction of the inlet flow containing a reacting mixture, and the stoichiometry of the mixture. The inlet temperature and stoichiometry (equivalence ratio) may in turn be combined to form a non-dimensional heat addition parameter. For each value of this parameter, the average total enthalpy ratio and total pressure ratio across the device are functions of only the reactant fill fraction. Performance over the entire operating envelope can thus be presented on a single plot of total pressure ratio versus total enthalpy ratio for families of the heat addition parameter. Total pressure ratios are derived from thrust calculations obtained from an experimentally validated, reactive Euler code capable of computing complete Pulse Detonation Engine limit cycles. Results are presented which demonstrate the utility of the described method for assessing performance of the Pulse Detonation Engine in several potential applications. Limitations and assumptions of the analysis are discussed. Details of the particular detonative cycle used for the computations are described.
\end{abstract}

\section{Introduction}

Pulse Detonation Engines (PDE's) are receiving much attention as a potential means for propulsion or as part of a propulsion system for future aerospace vehicles. One reason for this seems to be the promise of high

\footnotetext{
Senior Member, AIAA.

Copyright (C) 2001 by the American Institute of Aeronautics and Astronautics, Inc. No copyright is asserted in the United States under Title 17, U.S. Code. The U.S. Government has a royalty-free license to exercise all rights under the copyright claimed herein for Governmental Purposes. All other rights are reserved by the copyright owner.
}

efficiency due to the fact that PDE cycles operate with near-constant volume combustion. Furthermore, it is often argued that PDE's have fewer parts and are much less mechanically complex than other thrust producing systems (e.g., gas turbines). This, in turn makes them considerably less expensive. As yet however, there is very little experimental performance information in the literature to support the claims. What does exist has often been obtained from experiments that are not optimized for performance, or that are not self aspirating (i.e., air is forced through the inlet). ${ }^{1}$ Performance predictions based on such experimental results are not necessarily realistic. The analytical work is often greatly simplified and, as a result, somewhat optimistic. ${ }^{2,3}$ Furthermore, the analytical work tends to consider the PDE primarily as a stand-alone device, whereas many potential applications are envisioned in which it is a component in the propulsion system. Analysis of such systems requires a performance description of the PDE that can be combined with the additional components in a straightforward manner. Even in stand-alone applications, the PDE is typically seen as coupled to a nozzle (and an inlet), which is thermally limited. Analyses that neglect thermal limits and simply calculate say, specific thrust and impulse for a stoichiometric fuel/air mixture, are not realistic.

This paper introduces a method for describing the performance of a PDE cycle that can be readily applied to different propulsion systems. The method utilizes data from an experimentally validated, quasi-onedimensional, time-accurate, reactive, CFD Euler solver ${ }^{4-6}$ to provide results that are idealized due to the assumptions of the code, but realistic in that they capture the complex gas dynamics of the cycle." Furthermore, the use of a CFD code allows straightforward examination of many cycle modifications that can affect performance. For example, both partial filling and the addition of a nozzle at the

\footnotetext{
*Validation results from the code may be found in Appendix 1 of this paper.
} 
exhaust end of the PDE tube will be discussed in this paper. Additionally, a code can readily account for the fact that not all particles passing through a PDE necessarily go through the same thermodynamic cycle. A performance map is obtained from integrated quantities computed by the code. These are then mass or time-averaged to provide steady-state results. It will be shown that the PDE performance may be represented as a total pressure ratio that is a unique function of the total enthalpy ratio and a non-dimensional heat addition parameter.

The results presented herein are primarily for selfaspirated PDE cycles with constant cross section tubes, and with matched inlet total and exhaust static pressures; however, the method is not limited to this configuration. Similar maps can be generated for differing geometries and boundary conditions.

In the following sections, the method will be described and the utility of the resulting performance map will be demonstrated through the presentation of several simplified PDE system studies. The performance map description will be preceded by a listing of the assumptions and simplifications, a description of the particular PDE cycle under consideration, and a brief description of the Euler code with which performance data is generated. It is assumed that the reader is familiar with PDE cycles and numerical methods for computing them.

\section{Assumptions and Simplifications}

The assumptions and simplifications used in the code and analysis are listed below.

- The PDE flow is quasi-one-dimensional, inviscid and adiabatic.

- The PDE flow contains a combination of only reactant or product.

- Both reactant and product are calorically perfect gases with the same properties.

- All reactant (air/fuel combination) entering the PDE is at the prescribed mixture ratio.

- Valves on the PDE open and close instantaneously with no losses.

- Detonation occurs nearly instantaneously once reaction commences and is assured regardless of the mixture composition.

- The exhaust static pressure is identical to the inlet total pressure. Preliminary numerical simulations have shown that this boundary condition yields the highest performance.

\section{Code Description}

The numerical code used to generate data has been described in detail elsewhere in the literature. ${ }^{4-6}$ As such, only a brief description will be provided here, and only those aspects of the code relevant to the current investigation are presented.

\section{Governing Equations}

Under the assumptions listed above, the governing differential equations for the PDE tube may be written in non-dimensional form as

$$
\frac{\partial \overline{\mathrm{w}}}{\partial \mathrm{t}}+\frac{\partial \overline{\mathrm{F}}(\overline{\mathrm{w}})}{\partial \mathrm{x}}=\overline{\mathrm{S}}(\overline{\mathrm{w}}, \mathrm{x})
$$

where

$$
\left.\overline{\mathrm{W}}=\left[\begin{array}{c}
\rho \mathrm{A} \\
\rho \mathrm{uA} \\
\left(\frac{\mathrm{p}}{\gamma(\gamma-1)}+\frac{\rho \mathrm{u}^{2}}{2}+\mathrm{q}_{0} \rho \mathrm{z}\right.
\end{array}\right) \mathrm{A}\right]
$$

and

$$
\overline{\mathrm{F}}=\left[\begin{array}{c}
\rho \mathrm{AA} \\
\left(\frac{\mathrm{p}}{\gamma}+\rho \mathrm{u}^{2}\right) \mathrm{A} \\
\mathrm{u}\left(\frac{\mathrm{p}}{\gamma-1}+\frac{\rho \mathrm{u}^{2}}{2}+\mathrm{q}_{0} \rho \mathrm{z}\right) \mathrm{A} \\
\rho \mathrm{uzA}
\end{array}\right]
$$

The distance, $x$ has been normalized by the combustor length, $L$. The time, $t$ has been normalized by the characteristic wave transit time, $L / a^{*}$, where $a^{*}$ is the speed of sound at a chosen reference state. The pressure, $p$ and density, $\rho$ have been normalized by their respective reference values and the axial velocity, $u$ has been normalized by $a^{*}$. The mass fraction of reactant is $z$ and has a value between 0 and 1 . Note that $z$ can be related to, but is not the same as, actual fuel fraction. The ratio of specific heats is denoted by $\gamma$. For all of the results to be shown, the reference states are the inlet total conditions. The cross sectional area is $A$. The nondimensional heat of reaction $\mathrm{q}_{0}$ is defined as:

$$
\mathrm{q}_{0}=\frac{\Delta \mathrm{h}_{\mathrm{f}}}{(1+\mathrm{a} / \mathrm{f}) \mathrm{\gamma} \mathrm{R}_{\mathrm{g}} \mathrm{T}^{*}}
$$

where, $\Delta \mathrm{h}_{\mathrm{f}}$ is the fuel heat of reaction, $\mathrm{a} / \mathrm{f}$ is the air to fuel ratio, $R_{g}$ is the real gas constant, and $T^{*}$ is the reference temperature. 
For this non-dimensionalized form of the equations, the equation of state is written

$$
p=\rho T
$$

The speed of sound is simply $\sqrt{ } \mathrm{T}$.

The non-dimensional source vector is written as:

$$
\overline{\mathrm{S}}(\overline{\mathrm{w}}, \mathrm{x})=\left[\begin{array}{c}
0 \\
\frac{\mathrm{p}}{\mathrm{dA}} \\
\frac{\mathrm{dx}}{0} \\
-\mathrm{RA}
\end{array}\right]
$$

The reaction rate, $R$ of Eq. (6) has the form:

$$
R=K_{0} \rho z\left\{\begin{array}{cl}
1-\left(T_{i g n} / T_{i}\right) & ; T_{i}>T_{i g n} \\
0 & ; T_{i}<T_{i g n}
\end{array}\right\}
$$

where $\mathrm{K}_{0}$ is the reaction rate constant (normalized by the reference wave transit time), and $\mathrm{T}_{\mathrm{ign}}$ is the specified ignition temperature.

\section{Numerical Integration}

Equation (1) is integrated numerically with a secondorder accurate, Lax-Wendroff based scheme, utilizing Roe's approximate Riemann solver to obtain flux estimates at the cell faces. The scheme has excellent shock capturing capability and has been tested extensively with detonative calculations. Detonation properties such as the wave speed, and post-detonation temperature and pressure are correctly computed. Because of the TVD properties of the scheme and the simplicity of the combustion model, it is found that the peak pressure (the von Neumann spike) is somewhat under-predicted; however, this is of little consequence in the work here.

\section{Boundary Conditions}

The code has robust characteristic boundary condition routines such that subsonic, sonic, or supersonic inflow or outflow can occur at either end of the PDE tube. The routines contain logic that determines appropriate boundary conditions based on the current state of the interior cell and the imposed external pressure. Thus for example, the common situation in the PDE where the detonation wave, upon reaching the rear of the tube gives rise to supersonic, sonic, then subsonic flow is well behaved in the present code. Additionally, walltype conditions can be imposed at arbitrary times so that the valving process can be simulated. Application of boundary conditions in general are discussed in Ref. 7.
A discussion of issues specific to PDE's may be found in Ref. 8.

\section{Cycle Description}

All of the cycles computed in this study share some common features. Each, as mentioned previously, has the imposed exhaust pressure equal to the inlet total pressure. This does not necessarily mean that the computed exit pressure is the same as that imposed. For sonic and supersonic flows, the exit pressure will be determined from the interior of the computing domain. Each of the cycles is a limit cycle. That is, the code has been run until the developed wave cycle repeats itself indefinitely, and the integrated flux of mass into the device over one cycle, matches the integrated flux of mass out. Unless otherwise stated, each cycle completely empties and fills the tube once per cycle. There is no so-called partial filling. Numerical experiments have shown (and will be presented subsequently) that there is little thermodynamic advantage to a partial-fill cycle. The frequency increases, of course, but the fraction of the cycle that generates thrust remains approximately the same. Furthermore, partial filling leads to a situation where a significant fraction of the tube wall is constantly exposed to hot combustion gases (it is never washed by the cool unburned flow), which, although not dealt with in this paper, may not be practical when heat loads are considered. Each cycle accomplishes the filling and emptying process in the least amount of time possible. Thus, the inlet opens precisely when the internal pressure in the tube drops below the inlet total pressure, and closes precisely when the volume required to fill the tube has entered. Detonation is initiated immediately after the inlet is closed. The result is a cycle that occurs at the highest possible frequency. Detonation is initiated either by rapidly adding heat to the first numerical cell (via a source term) until Eq. (7) is satisfied, or by imposing a very brief (i.e. negligible mass and momentum flux) high pressure, high temperature boundary condition at the inlet. Either method yields similar results.

In order to illustrate the features described above, an example cycle is shown in Fig. 1. This figure shows contours of non-dimensional pressure, temperature, Mach number, and Reactant Fraction over the course of one PDE cycle. Thus, the horizontal dimension represents distance along the PDE tube. The vertical dimension represents time. The colors represent the values of the plotted quantities. Pressure and temperature are shown on a logarithmic scale in order to highlight details of the flowfield. Also shown in the figure, to the left of each contour are the highest and lowest value of the plotted quantity found in the entire 

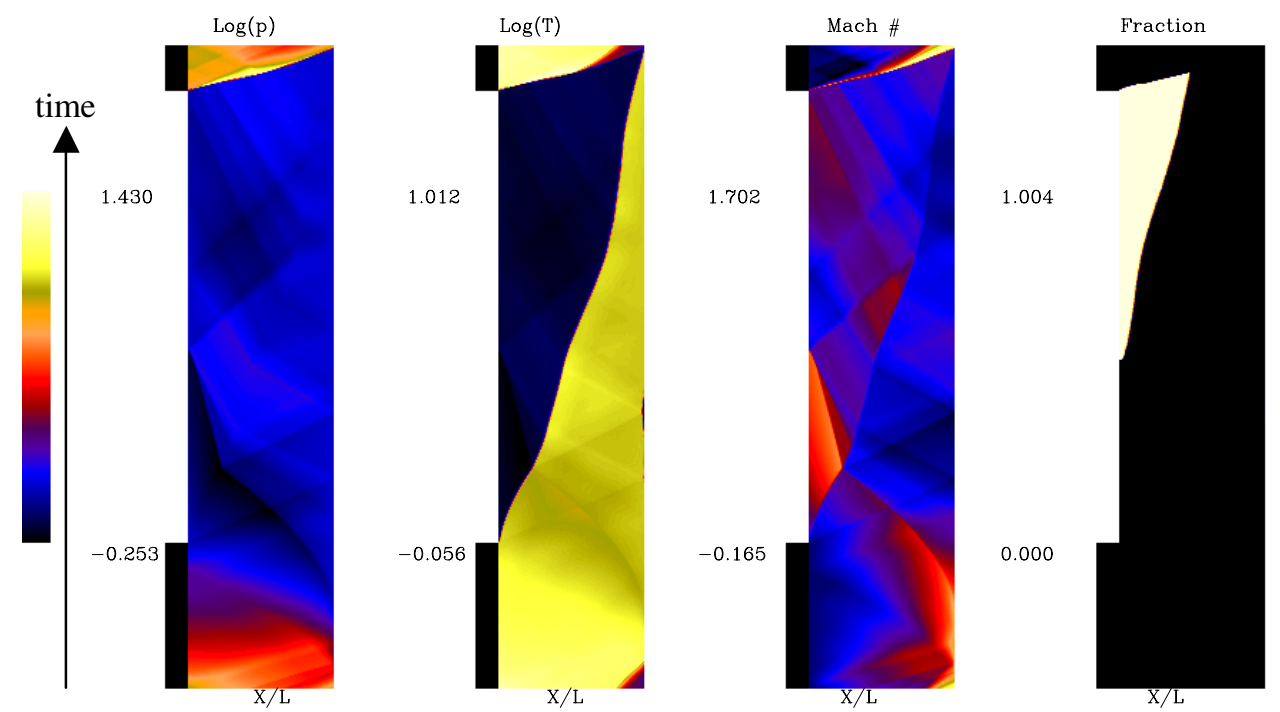

Fig. 1 Contours of $\log$ (pressure), $\log ($ temperature), Mach number, and detonable mixture fraction for one ideal PDE cycle with $\mathrm{q}_{0}=21.4$, at ambient inlet conditions, and a purge fraction $\mathrm{m}_{\text {reactant }} / \mathrm{m}_{\text {total }}$ of 0.51 . The non-dimensional time spanned is 3.74. The ratio of specific heats, $\gamma=1.3$.

$\mathrm{x}$-t space. Black rectangular regions on the left of each contour show the portion of the cycle over which the inlet was closed (i.e., a wall was present). The particular cycle shown is one for which the value of $\mathrm{q}_{0}=21.4$, representative of a stoichiometric fuel/air ratio, hydrocarbon fueled PDE flying Mach 1.5 at an altitude of approximately $30,00 \mathrm{ft}$. (i.e., inlet total temperature approximately $\left.600 \mathrm{R}, \Delta \mathrm{h}_{\mathrm{f}}=19,000 \mathrm{BTU} / \mathrm{lb}_{\mathrm{m}}, \mathrm{a} / \mathrm{f}=15.5\right)$. The ratio of reactant flow to total flow through the inlet is 0.49. That is, approximately half of the PDE tube is filled with a detonable mixture each cycle and the other half is filled with pure air. The ratio of specific heats used for the calculation was $\gamma=1.3$.

The path of the gas can be seen clearly in Fig. 1 by examining the temperature contour and the reactant fraction contour. The detonation path is visible in all of the contours, as is the transmitted shock that results when the detonation hits the unfueled region. Other features of note include the rather broad exit Mach number range over the course of the cycle and the surprisingly strong left-running shock originating on the right hand end after flow across the expansion fan has become subsonic.

For clarification purposes, it is noted that if the cycle shown in Fig. 1 was a partial fill cycle, the interface between hot reacted gases and cool unreacted gases (or pure air) would not extend completely across the tube as shown in the temperature contour. This results in a portion of the tube still containing hot gas at the detonative portion of the cycle begins. The process is shown in Fig. 2 which shows a contour of the temperature for a partial-fill cycle with $\mathrm{q}_{0}=28.2$. The ratio of reactant flow to total flow through the inlet is 0.48 . The fraction of the tube filled with either reactant or air is 0.80 .

\section{Performance Map Description}

Consider the ideal PDE cycle described above with ambient boundary conditions. The mass averaged total enthalpy of the exhaust flow may be written as

$$
\overline{\mathrm{H}}_{\mathrm{e}}=\frac{\int_{0}^{\mathrm{t}_{\text {cycle }}}(\mathrm{H} \rho \mathrm{u}) \mathrm{dt}}{\int_{0}^{t_{\text {evgle }}}(\rho \mathrm{u}) \mathrm{dt}}
$$

where $\mathrm{H}=\mathrm{h}+\frac{\mathrm{u}^{2}}{2}$ is the total enthalpy, and $\mathrm{t}_{\text {cycle }}$ is the (non-dimensional) time period of one cycle. The inlet total enthalpy is assumed known.

Integration of the mass energy, and species portion of Eq. (1) over one cycle, along with the stipulation that the cycle is a limit cycle will show that the ratio of mass averaged total exhaust enthalpy to inlet total enthalpy, HR, may be written as

$$
\frac{\overline{\mathrm{H}}_{\mathrm{e}}}{\overline{\mathrm{H}}_{\mathrm{i}}}=1+\mathrm{q}_{0}(\gamma-1)\left(1-\frac{\dot{\mathrm{m}}_{\text {air }}}{\dot{\mathrm{m}}_{\mathrm{i}}}\right)
$$




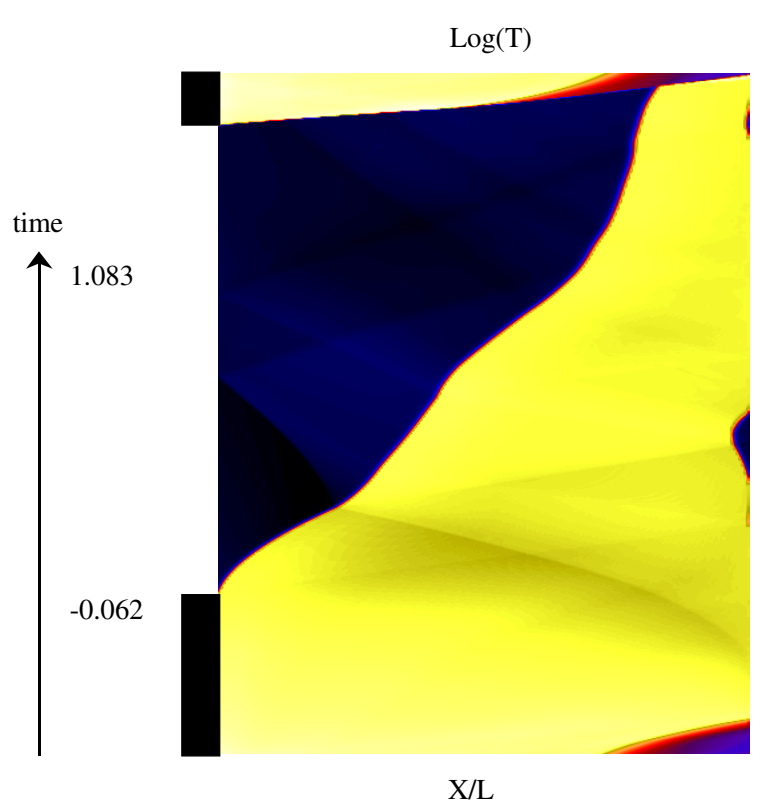

Fig. 2 Contour of $\log ($ temperature) for one ideal partial-fill PDE cycle with $q_{0}=28.2$, at ambient inlet conditions, and a purge fraction $\mathbf{m}_{\text {reactant }} / \mathbf{m}_{\text {total }}$ of 0.51. The non-dimensional time spanned is 3.27. The ratio of specific heats, $\gamma=1.3$. The fraction of the tube filled is 0.80 .

where the ratio $\frac{\overline{\dot{\mathrm{m}}}_{\text {air }}}{\overline{\dot{\mathrm{m}}}_{\mathrm{i}}}$, hereafter called the purge fraction is defined as

$$
\frac{\overline{\dot{m}}_{\text {air }}}{\overline{\dot{m}}_{\mathrm{i}}}=\frac{\int_{0}^{t_{\text {cycle }}}\left(\rho_{\text {air }} u_{\text {air }}\right) d t}{\int_{0}^{t_{\text {cycle }}}\left(\rho_{\mathrm{i}} u_{i}\right) d t}
$$

Here, the subscript air refers to the portion of the inlet flow which is pure air, and the subscript $i$ refers to the total inlet flow of air or reactant (air/fuel mixture).

Thus, the total enthalpy ratio is a function of the particular fuel, the ambient enthalpy or temperature, the stoichiometry and the purge fraction.

The time averaged thrust of a given cycle may be calculated as: ${ }^{9}$

$$
\frac{\overline{\mathrm{F}}}{\mathrm{p}_{0 \mathrm{i}}^{\prime} \mathrm{A}_{\mathrm{i}} \gamma}=\frac{\mathrm{mom}_{\mathrm{e}}}{\mathrm{t}_{\text {cycle }}}-\frac{\mathrm{p}_{\mathrm{oi}}}{\gamma}\left(\frac{\mathrm{A}_{\mathrm{e}}}{\mathrm{A}_{\mathrm{i}}}\right)
$$

where

$$
\operatorname{mom}_{\mathrm{e}}=\int^{\mathrm{t}_{\text {cycle }}}\left(\frac{\mathrm{p}_{\mathrm{e}}}{\gamma}+\rho_{\mathrm{e}} \mathrm{u}_{\mathrm{e}}^{2}\right)\left(\frac{\mathrm{A}_{\mathrm{e}}}{\mathrm{A}_{\mathrm{i}}}\right) \mathrm{dt}
$$

The subscript $e$ refers to the exit plane. The subscript $i$ refers to the inlet. The (dimensional) inlet total pressure is $\mathrm{p}_{0 \mathrm{i}}^{\prime}$. Note that the thrust calculated in this manner is greater than that which would be calculated using a thrust wall type integration ${ }^{10}$ such as

$$
\begin{aligned}
\frac{\overline{\mathrm{F}}}{\mathrm{p}_{0 \mathrm{i}}^{\prime} \mathrm{A}_{\mathrm{i}}}=\frac{1}{\mathrm{t}_{\text {cycle }}} \int^{\mathrm{t}_{\text {closed }}}\left(\mathrm{p}_{\text {wall }}-\mathrm{p}_{0 \mathrm{i}}\right) \mathrm{dt}+ \\
\frac{1}{\mathrm{t}_{\text {cycle }}} \iint\left(\mathrm{p}_{\text {wall }}-\mathrm{p}_{0 \mathrm{i}}\right) \frac{\mathrm{dA}}{\mathrm{A}_{\mathrm{i}}} \mathrm{dt}
\end{aligned}
$$

where the subscript wall refers to the thrust wall of the PDE and the subscript closed refers to the time period during which the inlet end of the PDE is closed.

The average exhaust total pressure, $\overline{\mathrm{p}}_{0 \mathrm{e}}$ for the device is then defined as the total pressure, at the total enthalpy defined by Eq. (9) that, when expanded through an ideal nozzle to the ambient pressure $\mathrm{p}_{0 \mathrm{i}}^{\prime}$ yields the same thrust as that calculated from Eq. (11). Thus, an average exit velocity $\overline{\mathrm{u}}_{\mathrm{e}}$ may be defined where:

$$
\frac{\bar{F}}{p_{0 i}^{\prime} A_{i} \gamma}=\frac{\bar{u}_{e}}{t_{\text {cycle }}}\left(\frac{A_{e}}{A_{i}}\right)^{t_{\text {cycle }}} \int \rho_{\mathrm{e}} u_{e} d t
$$

This may be combined with Eq. (11) to yield

$$
\overline{\mathrm{u}}_{\mathrm{e}}=\frac{\operatorname{mom}_{\mathrm{e}}-\frac{\mathrm{t}_{\text {cycle }} \mathrm{p}_{\mathrm{oi}}}{\gamma}\left(\frac{\mathrm{A}_{\mathrm{e}}}{\mathrm{A}_{\mathrm{i}}}\right)}{\mathrm{mf}_{\mathrm{e}}}
$$

where

$$
\mathrm{mf}_{\mathrm{e}}=\left(\frac{\mathrm{A}_{\mathrm{e}}}{\mathrm{A}_{\mathrm{i}}}\right)^{\mathrm{t}_{\mathrm{cycle}}} \int_{\mathrm{e}}^{\rho_{\mathrm{e}} \mathrm{dt}}
$$

With $\overline{\mathrm{u}}_{\mathrm{e}}$ known, and the average total enthalpy known from Eq. (9), the average total pressure may be obtained as

$$
\overline{\mathrm{p}}_{0 \mathrm{e}}=\mathrm{p}_{0 \mathrm{i}}\left(\frac{1}{1-\frac{\overline{\mathrm{u}}_{\mathrm{e}}^{2}}{2 \overline{\mathrm{H}}_{\mathrm{e}}}}\right)^{\frac{\gamma}{\gamma-1}}
$$




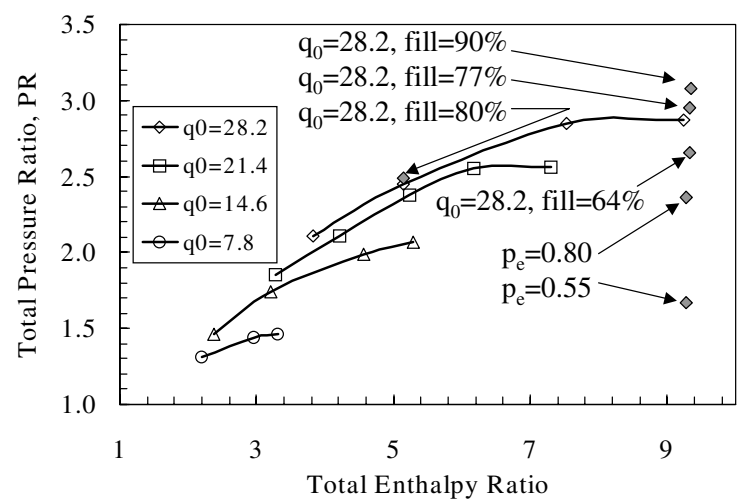

Fig. 3 Average total pressure ratio as a function of total enthalpy ratio for several families of $q_{0}$.

With the simplifications and cycle stipulations described earlier it can be seen from Eqns (9) and (17) that the ratio $\mathrm{PR}=\overline{\mathrm{p}}_{0 \mathrm{e}} / \mathrm{p}_{0 \mathrm{i}}$ is uniquely defined by $\mathrm{q}_{0}$ and the purge fraction. Figure 3 shows PR as a function of the enthalpy ratio (Eq. 9) for several families of the heat of reaction parameter $\mathrm{q}_{0}$. For each value of $\mathrm{q}_{0}$ the enthalpy ratio was varied by changing the purge fraction. The largest value of enthalpy ratio for each curve represents the minimum purge possible with the code (in order to avoid auto-ignition) of approximately $2 \%$. The minimum enthalpy ratio represents an arbitrarily chosen maximum purge fraction of approximately $70 \%$, except for the $\mathrm{q}_{0}=7.8$ case where it was $50 \%$. All of the calculations were made using a PDE tube of uniform cross section. The ratio of specific heats for all calculations was $\gamma=1.3$. The number of numerical cells used in all of the calculations to be shown was 200. It can be seen that for a specified temperature ratio, the higher the purge fraction, the better the performance. Also shown in the figure are results from several cycles computed with constant $\mathrm{q}_{0}=28.2$, but with fill fractions other than 1 (i.e., partial fill cycles). The fill fraction is defined as the fraction (or percentage) of the tube filled with either air or detonable mixture each cycle. The points with fill fractions of 90,77 , and $64 \%$ were computed using minimum purge fractions. The point with a fill fraction of $80 \%$ was computed for a purge fraction of $51 \%$. It can be seen that the partial fill cycles, for the most part, offer no performance enhancement. The one exception in the computed data occurs when the fill fraction is $90 \%$. The reason for this appears to be related to the timing of certain waves in the system. For this particular cycle a shock wave impinges on the thrust wall at precisely the moment that the detonation is initiated.

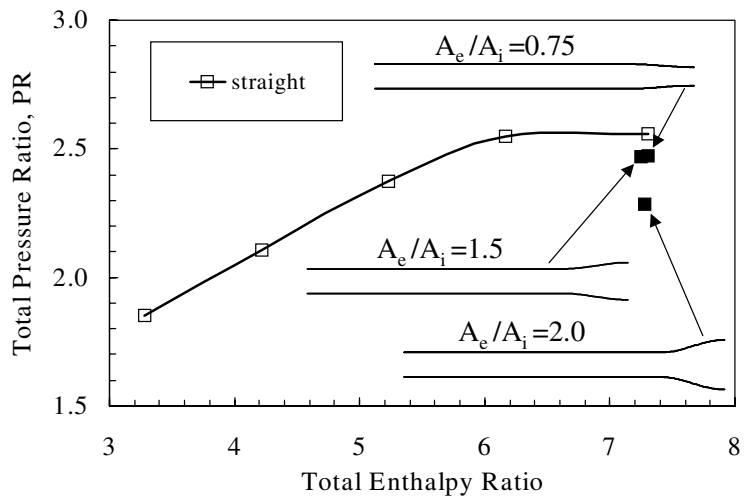

Fig. 4 Average total pressure ratio as a function of total enthalpy ratio for several ideal PDE tube geometries. In each case $\mathrm{q}_{0}=21.4$, the purge fraction is a minimum, and $\gamma=1.3$.

More investigation is needed with regard to such tuning of the wave system; however, the gains, if any, appear quite modest.

Figure 3 also shows two cycles computed with constant $\mathrm{q}_{0}=28.2$, but with reduced exit pressure. The exit pressures used (relative to the inlet total pressure) were 0.80 and 0.55 as shown in the figure. It is noted that when calculating total pressures from Eqns. (15) and (17) the back pressure values were used in place of the term $\mathrm{p}_{0 \mathrm{i}}$. It can be seen that reducing the back pressure reduces overall pressure ratio (and thus performance) for a given enthalpy ratio. This is the reason, as stated earlier, that PDE cycles with exit pressure equal to inlet total pressure were used in the present study.

\section{Preliminary Geometry Variations}

Because the performance data for the map of Fig. 3 comes from a Q-1-D code, it is a relatively easy matter to look at geometric variations in the PDE design. For example, examination of Fig. 1 reveals that a substantial portion of the exit flow is sonic or supersonic. This suggests that the flow cannot fully expand within the tube, leading to reduced performance. An intuitive solution may be to provide a 'nozzle' section at the exit end of the PDE that (from a steady state perspective) would allow full expansion. Figure 4 shows the results of such an exercise. Computations were performed for three different geometries, all using minimum purge, and all with $\mathrm{q}_{0}=21.4$. The geometries are shown in Fig. 4. All three tubes had uniform cross sectional area from $0 \leq x / L \leq 0.8$. From there to $x / L=1.0$ they varied smoothly from $A_{e} / A_{i}=1.0$ to $A_{e} / A_{i}=0.75,1.5$, and 2.0. For the geometries examined, there does not appear to be any performance enhancement. These results appear 


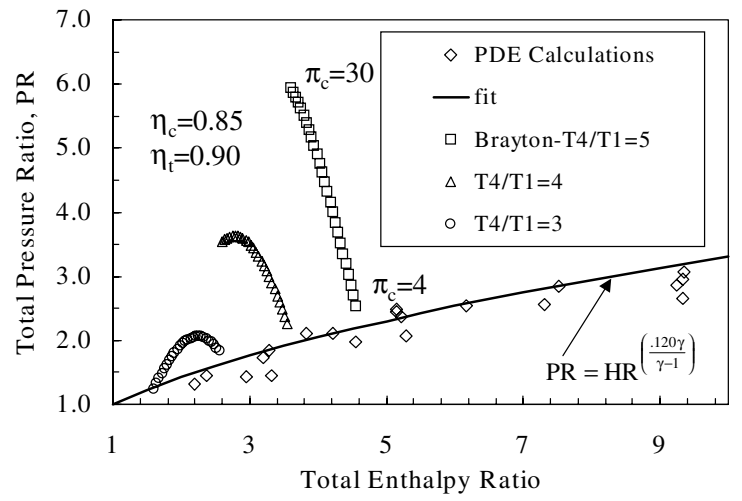

Fig. 5 Comparison of average total pressure ratio as a function of total enthalpy ratio for PDE and Brayton cycles. The ratio of specific heats, $\gamma=1.3$.

consistent with similar computations made in Ref. 11 for a rocket based PDE. They suggest that sonic or slightly supersonic exit flow is a fundamental attribute of PDE cycles and that its effects should be included in any idealized performance estimates. Clearly, a more thorough examination is needed in order to draw conclusive results; however, it can be seen that the use of a CFD-based model for performance evaluation, as suggested in this paper is flexible, and of great utility.

\section{Application}

With the performance of the PDE in the form described above, analysis for a variety of applications is readily possible.

\section{Simple Brayton Cycle Comparison}

The PDE cycle is often compared with the Brayton cycle, the latter being representative of conventional turbomachinery-based propulsion systems. When this comparison is made however, it is not always clear that the parameters held in common are meaningful. What, for example is the equivalent state in a PDE cycle to the Compressor discharge of a Brayton cycle? Figure 5 shows a comparison in terms that are unambiguous. The performance of each cycle is plotted as PR versus HR as in Figs. 3 and 4. For the PDE cycle, all of the computed data has been plotted along with a simple curve fit defined by

$$
\mathrm{PR}=\mathrm{HR} \mathrm{(}^{\left(\frac{.120 \gamma}{\gamma-1}\right)}
$$

This curve-fit further simplifies the computed results by assuming that, for the most part, varying HR by either $\mathrm{q}_{0}$ or purge fraction yields equivalent results. It is noted that the form of Eq. (18) has no theoretical basis and has not been tested for other values of $\gamma$. It is intended purely as a convenient fit for the data at hand.

Also shown in Fig. 5 are the results from a simple Brayton cycle calculation ${ }^{12}$ with compressor and turbine adiabatic efficiencies set to 0.85 and 0.90 respectively. The Brayton cycle results are shown for families of $T_{4} / T_{1}$, which is the ratio of turbine inlet temperature to compressor inlet temperature. For each family, the compressor pressure ratio $\pi_{\mathrm{c}}$ has been varied from 4 to 30 , which is representative of modern turbomachinery. Since cycle efficiency increases monotonically with PR, it is clear that, within the temperature range of conventional turbomachinery shown, the Brayton cycle is more efficient than the PDE cycle as computed in this paper. To achieve higher temperature ratios, a Brayton cycle with an afterburning process would be required. This is discussed in the next example.

\section{PDE With Inlet and Nozzle}

As a second example of the application of the performance methodology, consider a PDE (or series of PDE tubes) with only an ideal inlet and nozzle fore and aft. Such a configuration may be envisioned for a high speed, Mach 0-5 aircraft. Standard thermodynamic analysis $^{12}$ and Fig. 3, or more easily, Eq. (18), may be used to calculate the specific thrust and specific impulse over the Mach number regime. The results are shown in Figs 6 and 7. A Mach number dependent static inlet temperature profile was used for these calculations in order to account for altitude effects. The assumed profile was $520 \mathrm{R}$ at static conditions, $400 \mathrm{R}$ for Mach 2.0 and above, and a linear variation between these values. The nozzle inlet total temperature was chosen to be $4200 \mathrm{R}$. The ratio of specific heats was 1.3. For Fig. 6 the fuel heating value was $19000 \mathrm{BTU} / \mathrm{lbm}$.

Also shown in the Figs. 6 and 7 are the performance results for a ramjet and for afterburning turbojets with compressor pressure ratios of 30 and 4 . For the turbojet calculations the compressor and turbine adiabatic efficiencies were again 0.85 and 0.90 respectively. The combustor and afterburner were assumed loss free (i.e., constant total pressure). The turbine inlet temperature was $3000 \mathrm{R}$. It can be seen that the ideal PDE performance is fairly consistent over the Mach number regime and that it is comparable with a nonideal, afterburning turbojet having a compressor pressure ratio of 4.0. For turbojets of a more realistic pressure ratio, the PDE shows significantly less specific thrust and specific impulse. For the Ramjet, the performance advantages of a PDE are clear at Mach numbers below 3.0. Beyond this, there does not appear 


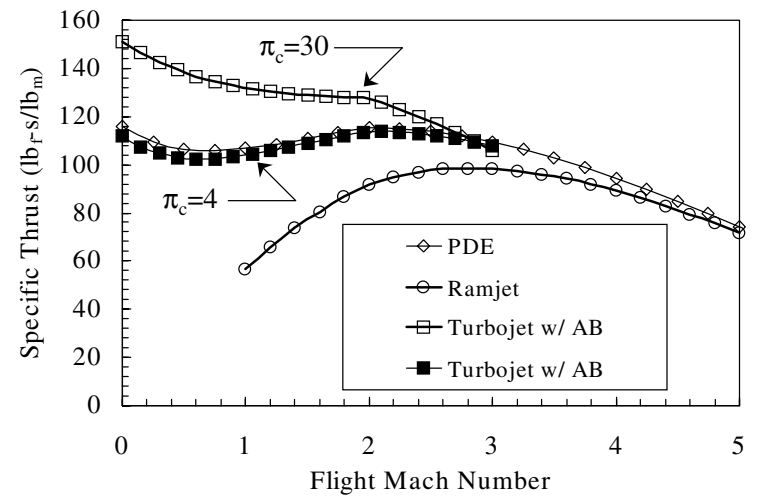

Fig. 6 Specific thrust as a function of Mach Number for PDE, Ramjet and Turbojet with Afterburner. For all systems $\gamma=1.3$, inlet and nozzle are ideal, and the nozzle inlet temperature is $\mathbf{4 2 0 0}$ R. For the Turbojet, adiabatic compressor and turbine efficiencies are 0.85 and 0.90 respectively. The turbine inlet temperature is $3000 \mathrm{R}$.

to be significant benefit. These PDE performance results are below what is typically listed in the literature ${ }^{2,3,13}$ however, because they represent computed results, from a validated code, it can be argued that they are more representative of an 'idealization' in the sense of being as good as can be expected.

\section{PDE Afterburner}

As a final example of the utility of the above performance mapping methodology, consider a PDE as a replacement for a turbojet afterburner. This concept holds promise since the total pressure rises across a PDE and falls across a conventional afterburner. Therefore, a PDE afterburner should yield improved performance. With Eqn. (18) in hand, the results are obtained in much the same manner as those for the turbojet of the previous example. Figures 8 and 9 show the specific thrust and specific impulse over the same Mach number regime as Figs. 6 and 7. The same temperature limits and efficiencies were imposed on the turbomachinery and nozzle. A compressor pressure ratio of 30 was used. The PDE afterburner, as expected shows improvement in terms of increased specific thrust and impulse over the conventional afterburner. The benefits; however, are surprisingly modest. The reason for this is the relatively low enthalpy ratio occurring across the afterburner (for these calculations it was between 1.8 and 2.5). This, in turn, leads to a lower pressure ratio. It is interesting to note that even with the nozzle temperature restriction removed, the incoming temperature is relatively high. From Eqn. (4) this yields, even for stoichiometric mixtures, very low values of $\mathrm{q}_{0}$.

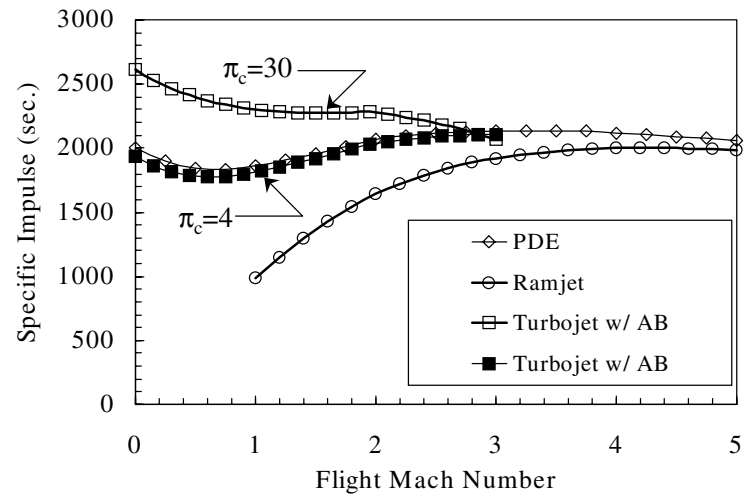

Fig. 7 Specific Impulse as a function of Mach Number for PDE, Ramjet and Turbojet with Afterburner. For all systems $\gamma=1.3$, inlet and nozzle are ideal, and the nozzle inlet temperature is $\mathbf{4 2 0 0}$ R. For the Turbojet, adiabatic compressor and turbine efficiencies are 0.85 and 0.90 respectively. The turbine inlet temperature is $3000 \mathrm{R}$. The fuel heating value is $19,000 \mathrm{BTU} / \mathrm{lbm}$.

Low values of $\mathrm{q}_{0}$ in turn lead to low enthalpy and pressure ratios as shown in Fig. 3.

\section{Discussion}

Other PDE applications may be examined in a straightforward manner using the map of Fig. 3. Examples would include gas turbine topping cycles, bypass duct afterburners, even ejector based cycles (if some assumptions are made regarding the work transfer process).

Of the applications that have been examined, the process has been made easier through the use of Eq. (18); however, it should be kept in mind that for a given application, not all values of $\mathrm{q}_{0}$ (and therefore enthalpy ratio are possible). This was pointed out in the afterburning PDE example but may appear elsewhere as well. For the PDE with inlet and nozzle, the inlet temperature at Mach 5 is $1900 \mathrm{R}$. Because of the $4200 \mathrm{R}$ thermal limit placed on the nozzle, the maximum enthalpy ratio was 2.21 . Using a fuel heating value of 19,000 BTU/lbm and a stoichiometric air/fuel ratio of 15.5 however, would lead to a value of $\mathrm{q}_{0}=6.8$. Examination of Fig. 3 shows that this heating value yields an enthalpy ratio in the vicinity of 2.5-3. Thus, the nozzle temperature restriction need not be in place, because the enthalpy ratio is already limited.

Similar limitations would apply in a topping cycle application. For example, a small gas turbine with a pressure ratio of 8 has a discharge temperature at sea level of approximately $1000 \mathrm{R}$. If the maximum turbine 


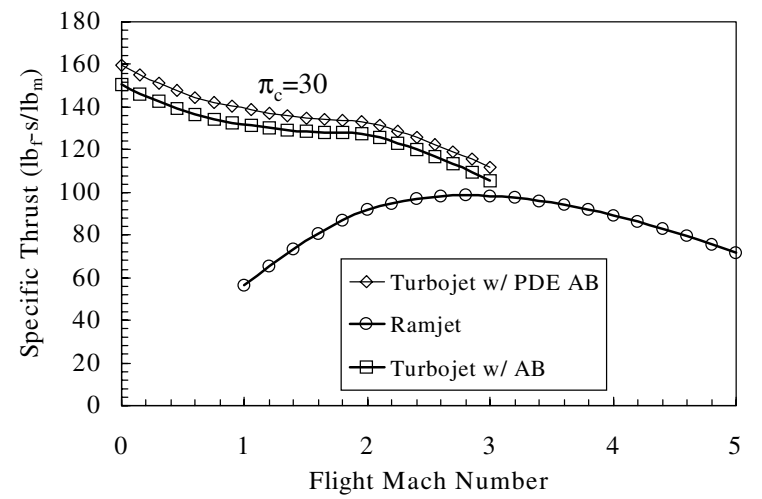

Fig. 8 Specific thrust as a function of Mach Number for Turbojet with PDE Afterburner, Turbojet with conventional Afterburner, and Ramjet. For all systems $\gamma=1.3$, inlet and nozzle are ideal, and the nozzle inlet temperature is $4200 \mathrm{R}$. For the Turbojet, adiabatic compressor and turbine efficiencies are 0.85 and 0.90 respectively. The turbine inlet temperature is $3000 \mathrm{R}$.

inlet temperature is $2400 \mathrm{R}$ then the enthalpy ratio is 2.4. This is achievable from Fig. 3 using some purge and/or a lean mixture. Alternately, the PDE may be considered as the primary source for an ejector, such that the PDE operates stoichiometrically with no purge and mixes with bypass air, the mixture being ultimately presented to the high-pressure turbine. Using the heating value and air/fuel ratio from the previous example however, yields a maximum $\mathrm{q}_{0}$ of 12.9. This in turn implies a maximum primary stream enthalpy ratio of only 4.8 and a maximum entrainment ratio (bypass flow divided by PDE flow) of 1.7. The thrust augmentation for an ejector system with an entrainment ratio of 1.7 is, from Ref. 14, between an ideal of 1.64 and a data fit of 1.33. Using the average of these two and Eqns. 11-17 it can be shown that the PDE/ejector yields a pressure ratio of 1.61 compared to a value of 1.58 for the PDE alone at an enthalpy ratio of 2.4. Thus, in this case the ejector system would offer no thermodynamic advantage over the PDE alone because of the limited $\mathrm{q}_{0}$.

Other limits may be placed on the map of Fig. 3. It was noted that mixture detonability was not considered in the CFD model, yet detonability limits clearly exist. A number of fuels may be limited to mixtures near stoichiometric values. Material temperature limits will also limit the range of enthalpy ratios. For cycles with a purge fraction of zero, it can be expected that the peak uncooled wall temperature is approximately $90 \%$ of the mass averaged exhaust temperature.

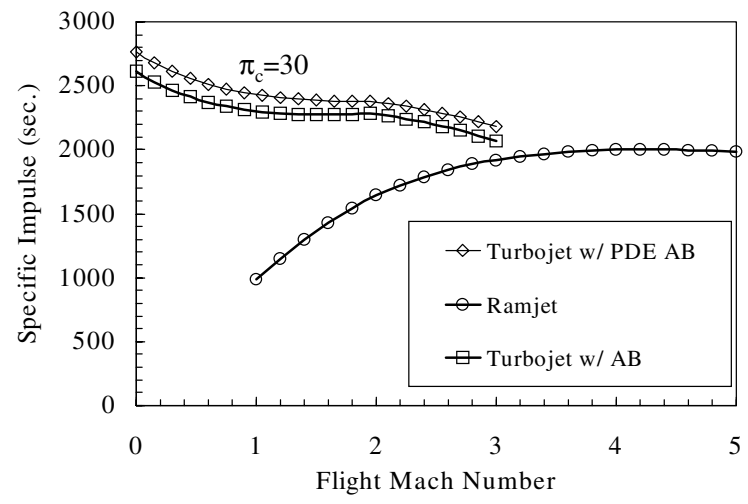

Fig. 9 Specific Impulse as a function of Mach Number for Turbojet with PDE Afterburner, Turbojet with conventional Afterburner, and Ramjet. For all systems $\gamma=1.3$, inlet and nozzle are ideal, and the nozzle inlet temperature is $4200 \mathrm{R}$. For the Turbojet, adiabatic compressor and turbine efficiencies are 0.85 and 0.90 respectively. The turbine inlet temperature is $3000 \mathrm{R}$. The fuel heating value is $19,000 \mathrm{BTU} / \mathrm{lbm}$.

In closing this section of the paper, it is noted that during the course of developing the map, the performance impact of several aspects of the PDE cycle (purge, partial-fill, geometry, back pressure) have been, to a greater or lesser extent, examined. All of these aspects however, have been in the context of a particular gasdynamic cycle. It should be kept in mind that other cycles, such as PDE cycles with valves at the back (or low-loss variable back-pressure systems) may provide much different, and superior performance to the one presented.

\section{Conclusions}

It has been demonstrated in this paper that idealized airbreathing PDE performance can be mapped onto a single plot of total pressure ratio versus total enthalpy ratio. It has further been shown that this format is useful in system studies since the PDE can be viewed as simply another 'component' with straightforward input and output. The idealized PDE performance data was obtained from a quasi-one-dimensional CFD code and it has been shown that this is a more realistic approach than purely analytical methods. The performance shown is generally below that which has been previously reported for so-called 'idealized' PDE performance but is still idealistic in that the losses captured are only those endemic to the cycle. A similar map could easily be generated which incorporates losses such as those due to heat transfer, viscous effects and valving. 


\section{References}

1. Schauer, Fred, Stutrud, Jeff, Bradley, Royce, "Detonation Initiation Studies and Performance Results for Pulsed Detonation Engine Applications" AIAA Paper 2001-1129, January 2001.

2. Heiser, W.H and Pratt, D.T. "Thermodynamic Cycle Analysis of Pulse Detonation Engines," submitted for publication in the AIAA Journal of Propulsion and Power, 2001.

3. Kentfield, J.A.C., "The Fundamentals of Idealized Air-Breathing Pulse-Detonation Engines," AIAA Paper 2000-3469, July 2000.

4. Nalim, R.M. and Paxson, D.E., "A Numerical Investigation of Premixed Combustion in Wave Rotors," ASME Journal of Engineering for Gas Turbines and Power, Vol. 119, No. 3, 1997, pp. 668-675, also ASME Paper 96-GT-116, June 1996, also, NASA TM-107242.

5. Paxson, D.E., "Numerical Simulation of Dynamic Wave Rotor Performance," AIAA Journal of Propulsion and Power, Vol. 12, No. 5, September 1996, pp 949-957.

6. Paxson, D.E., "Numerical Assessment of Four-Port Through-Flow Wave Rotor Cycles With Passage Height Variation," AIAA paper 97-3142, July 1997.

7. Paxson, D.E., "A General Numerical Model for Wave Rotor Analysis," NASA TM-105740, July 1992.
8. Wilson, J. and Paxson, D.E., "On the Exit Boundary Condition for One-dimensional Calculations of Pulsed Detonation Engine Performance," to be presented at the 18th International Colloquium on the Dynamics of Explosions and Reactive Systems, July 29, 2001, Seattle, Washington.

9. Foa, J.V., Elements of Flight Propulsion, John Wiley and Sons, 1960.

10. Bussing, T. and Pappas, G., "An Introduction to Pulse Detonation Engines," AIAA paper 94-0263, January 1994.

11. Mohanraj, R. and Merkle, C.L., "A Numerical Study of Pulse Detonation Engine Performance," AIAA paper 2000-0315, January 2000.

12. Oates, Gordon, C., Aerothermodynamics of Gas Turbine and Rocket Propulsion, American Institute of Aeronautics and Astronautics, 1997.

13. Kailasanath, K., "A Review of PDE ResearchPerformance Estimates," AIAA paper 2001-0474, January 2001.

14. Porter, J.L., and Squyers, R.A., "A Summary/ Overview of Ejector Augmentor Theory and Performance," Contractor Report R-91100/9CR47A, September 1979. 


\section{Appendix 1: Code Validation}

The following two figures compare data from the code used in this paper to that from a direct-connect, Hydrogen/Air PDE experiment currently operating at the Air Force Research Laboratory in Dayton, Ohio. ${ }^{1}$ Although not described in this paper, the code contains sub-models to account for the effects of fluid viscosity, heat transfer, and valving. Those sub-models were employed in following comparison unless otherwise noted. Descriptions of the sub-models may be found in the literature. ${ }^{4,5}$

A molecular weight of $\hat{M}=21 \mathrm{lbm} / \mathrm{lbmole}$ was used for all computations (except those for rich mixtures). The ratio of specific heats was $\gamma=1.3$. The heating value of the fuel was assumed to be 51,571 BTU/lbm. Ambient pressure was 14.7 psia. Inlet temperature was approximately $520 \mathrm{R}$. The number of numerical cells used in the computation was 200 .

Figure A1 shows the measured and computed thrust and specific impulse, $I_{\mathrm{sp}}$ as a function of equivalence ratio, $\phi$ for a $16 \mathrm{hz}$. cycle in which $100 \%$ of the tube is filled with detonable mixture and $50 \%$ of the tube is filled with purge air each cycle (i.e., the purge air simply passes through the tube without any interaction with the detonation). Open symbols represent measured results. Solid symbols represent computed results. The agreement is fairly good. The largest disparity is between $\phi=0.8$ and 1.0. For comparison, the code was also run at two different equivalence ratios (1.0 and 0.5) with heat transfer and viscous sub-models 'turned off'. This data is shown as gray solid symbols. It is clear that the effect is quite substantial.

Figure A2 shows the measured and computed thrust and $I_{s p}$ as a function of the fill fraction for a $16 \mathrm{hz}$. cycle running a stoichiometric mixture, with $50 \%$ purge air. Again, the agreement is quite reasonable.

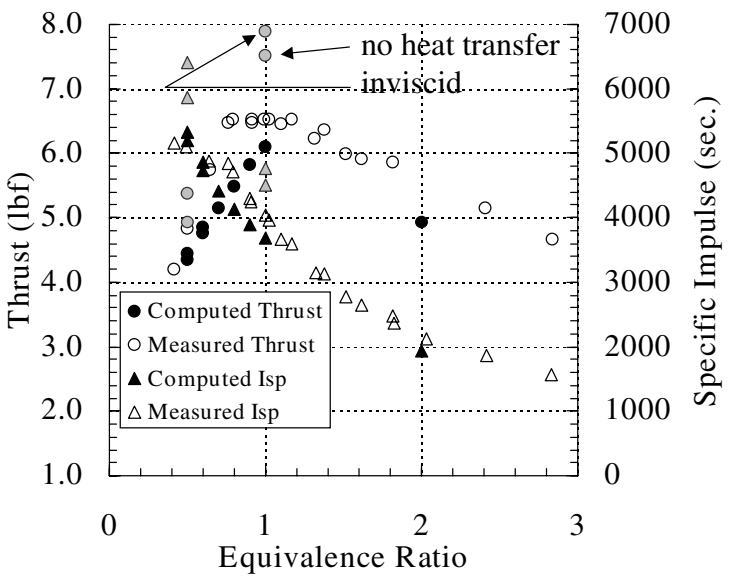

Fig. A1 Measured and computed thrust and $I_{s p}$ as a function of equivalence ratio for a at $100 \%$ fill; $50 \%$ purge; $16 \mathrm{hz}$. cycle (of one of the four tubes).

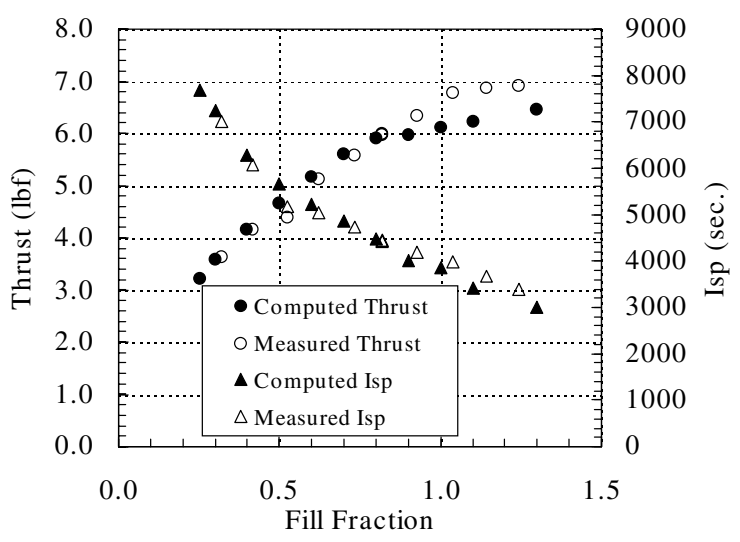

Fig. A2 Measured and computed thrust and $I_{\text {sp }}$ as a function of Fill Fraction; 50\% purge; $16 \mathrm{hz}$. cycle; $\phi=1.0$ (one of the four tubes). 
Public reporting burden for this collection of information is estimated to average 1 hour per response, including the time for reviewing instructions, searching existing data sources, gathering and maintaining the data needed, and completing and reviewing the collection of information. Send comments regarding this burden estimate or any other aspect of this collection of information, including suggestions for reducing this burden, to Washington Headquarters Services, Directorate for Information Operations and Reports, 1215 Jefferson Davis Highway, Suite 1204, Arlington, VA 22202-4302, and to the Office of Management and Budget, Paperwork Reduction Project (0704-0188), Washington, DC 20503.

\begin{tabular}{|l|l|l}
\hline 1. AGENCY USE ONLY (Leave blank) & $\begin{array}{c}\text { 2. REPORT DATE } \\
\text { July } 2001\end{array}$ & $\begin{array}{r}\text { 3. REPORT TYPE AND DATES COVERED } \\
\text { Technical Memorandum }\end{array}$ \\
\hline
\end{tabular}

4. TITLE AND SUBTITLE 5. FUNDING NUMBERS

A Performance Map for Ideal Air Breathing Pulse Detonation Engines

6. AUTHOR(S)

Daniel E. Paxson

WU-708-48-13-00

\section{PERFORMING ORGANIZATION NAME(S) AND ADDRESS(ES)}

National Aeronautics and Space Administration

John H. Glenn Research Center at Lewis Field

Cleveland, Ohio 44135-3191

8. PERFORMING ORGANIZATION REPORT NUMBER

E-12929

\section{SPONSORING/MONITORING AGENCY NAME(S) AND ADDRESS(ES)}

National Aeronautics and Space Administration

Washington, DC 20546-0001

10. SPONSORING/MONITORING AGENCY REPORT NUMBER

NASA TM-2001-211085

AIAA-2001-3465

\section{SUPPLEMENTARY NOTES}

Prepared for the 37th Joint Propulsion Conference and Exhibit cosponsored by the AIAA, ASME, SAE, and ASEE, Salt Lake City, Utah, July 8-11, 2001. Responsible person, Daniel E. Paxson, organization code 5530, 216-433-8334.

12a. DISTRIBUTION/AVAILABILITY STATEMENT 12b. DISTRIBUTION CODE

Unclassified - Unlimited

Subject Category: 07

Distribution: Nonstandard

Available electronically at http://gltrs.grc.nasa.gov/GLTRS

This publication is available from the NASA Center for AeroSpace Information, 301-621-0390.

13. ABSTRACT (Maximum 200 words)

The performance of an ideal, air breathing Pulse Detonation Engine is described in a manner that is useful for application studies (e.g., as a stand-alone, propulsion system, in combined cycles, or in hybrid turbomachinery cycles). It is shown that the Pulse Detonation Engine may be characterized by an averaged total pressure ratio, which is a unique function of the inlet temperature, the fraction of the inlet flow containing a reacting mixture, and the stoichiometry of the mixture. The inlet temperature and stoichiometry (equivalence ratio) may in turn be combined to form a nondimensional heat addition parameter. For each value of this parameter, the average total enthalpy ratio and total pressure ratio across the device are functions of only the reactant fill fraction. Performance over the entire operating envelope can thus be presented on a single plot of total pressure ratio versus total enthalpy ratio for families of the heat addition parameter. Total pressure ratios are derived from thrust calculations obtained from an experimentally validated, reactive Euler code capable of computing complete Pulse Detonation Engine limit cycles. Results are presented which demonstrate the utility of the described method for assessing performance of the Pulse Detonation Engine in several potential applications. Limitations and assumptions of the analysis are discussed. Details of the particular detonative cycle used for the computations are described.

14. SUBJECT TERMS 15. NUMBER OF PAGES

Pulse detonation; Computational fluid dynamics; Propulsion 17

\begin{tabular}{|c|c|c|}
\hline $\begin{array}{c}\text { 17. SECURITY CLASSIFICATION } \\
\text { OF REPORT } \\
\text { Unclassified }\end{array}$ & $\begin{array}{c}\text { 18. SECURITY CLASSIFICATION } \\
\text { OF THIS PAGE } \\
\text { Unclassified }\end{array}$ & $\begin{array}{c}\text { 19. SECURITY CLASSIFICATION } \\
\text { OF ABSTRACT } \\
\text { Unclassified }\end{array}$ \\
\hline
\end{tabular}

